\title{
Is Inflation Persistence Different in Reality?
}

\author{
Nikolaos Antonakakis*, Webster University, Wien, Austria and University of \\ Portsmouth, Portsmouth, United Kingdom \\ Juncal Cunado $^{* *}$, University of Navarra, Pamplona, Spain \\ Luis A. Gil-Alana***, University of Navarra, Pamplona, Spain \\ Rangan Gupta, University of Pretoria, Pretoria, South Africa
}

\begin{abstract}
This study examines the inflation persistence using both online and official price indexes in Argentina, Brazil, China, Japan, Germany, South Africa, the UK and the US, using fractional integration technique. The main results suggest that the degree of persistence, estimated by the long-memory parameter, is smaller when using online price indexes (believed to be a more realistic measure of inflation), mainly in the cases of Argentina, Brazil, China and the UK. Monetary policy implications are discussed.

JEL classification: C22, E43, G12.
\end{abstract}

Keywords: Official and online consumer price indexes; fractional integration; persistence.

\footnotetext{
* Corresponding author. University of Portsmouth, Economics and Finance Group, PO1 3DE, Portsmouth, United Kingdom. Email: nikolaos.antonakakis@port.ac.uk. Tel: +44 (0)23 9284 4261. Webster Vienna Private University, Department of Business and Management, 1020, Vienna, Austria. Email: nikoalos.antonakakis@webster.ac.at. Tel: +43-1-2699293-4373.

** Juncal Cuñado gratefully acknowledges financial support from the Ministerio de Economía y Competitividad (ECO2014-55496).

*** Luis A. Gil-Alana gratefully acknowledges financial support from the Ministerio de Economía y Competitividad (ECO2014-55236).
} 


\section{Introduction}

The degree of inflation persistence is a relevant parameter of interest for different reasons. First, it plays a key role in the design of monetary policy, since it will determine the degree to which monetary policy authorities can maintain a stable level of output and inflation simultaneously, and thus, the performance of monetary policy (Rudebusch, 2002; Levin and Williams, 2003; Amano, 2007). Furthermore, and given the different implications of macroeconomic models (Dornbush, 1976; Galí and Gertler, 1999; Christiano et al., 2005), an accurate estimate of inflation persistence will help us understand to what extent the different macroeconomic models are consistent with the empirical evidence. Both of these reasons explain the ample literature on the econometric modeling of this variable (Nelson and Schwert, 1977; Barsky, 1987; Hassler and Wolters, 1995; Hsu, 2005; Lee, 2005; Noriega and Ramos-Francia, 2009; Cuestas and Harrison, 2010; Hassler and Meller, 2014). However, despite the vast literature directed to estimate the integration order or persistence of this variable, the results are not yet conclusive (see, for example, Martins and Rodrigues, 2014, for a recent survey of the literature). One common characteristic of all these papers is the use of official Consumer Price Indexes (CPI) published by national agencies (US Bureau of Labor Statistics for U.S prices, Instituto Nacional de Estadística y Censos for CPI in Argentina, and so on), or international institutions, such as the International Monetary Fund, the World Bank or the Organization for Economic Co-operation and Development.

Accurately measuring prices and inflation has been a major concern among academics and different statistical agencies over the last fifty years (Griliches, 1961; Diewert, 1976, 1995; Hausman, 1997; Gordon and Griliches, 1997; Abraham, 1997; Boskin and Jorgerson, 1997) due to several factors, such as the existence of a millions of goods and services, the change in the quality of these goods or the introduction of new 
products in the market ${ }^{1}$. More recently, and following Cavallo (2013), who used online price data to provide alternative price indexes to the official ones in Argentina, online price indexes are being collected (see the Billion Prices Project at MIT,

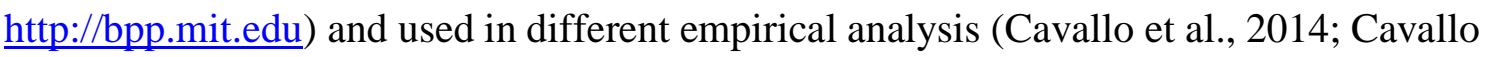
and Rigodon, 2016; Gorodnichenko et al., 2014; Gorodnichenko and Talavera, 2014; Alvarez et al., 2016). However, determining whether these two inflation measures (those based on official CPI and those based on online price indexes) have distinct dynamics is still an open question (Cavallo and Rigodon, 2016).

In this context, the objective of this note is to test whether there are significant differences in the degree of persistence using these two measures of inflation in a sample of countries that include Argentina, Brazil, China, Germany, Japan, South Africa, the United Kingdom (UK) and the United States of America (US), by means of applying fractional integration techniques. To the best of our knowledge, this is the first paper that tries to test whether there are differences in the degree of inflation persistence when official CPI indexes and online prices are used to calculate inflation rates in this sample of countries.

Our results indicate that the degree of inflation persistence, estimated by the longmemory parameter, is smaller when using online price indexes (that is believed to be a more realistic measure of inflation), mainly in the cases of Argentina, Brazil, China and the UK.

The remainder of the paper is structured as follows: Section 2 describes the methodology. Section 3 presents the data and the main empirical results, while Section 4 contains some concluding comments and policy implications.

\footnotetext{
1 The Journal of Economic Perspectives, 1998, vol. 12, published a number of papers that deal with the difficulties of accurately measuring the CPI.
} 


\section{Methodology}

The methodology used in this paper is based on the concept of fractional integration. For this purpose, we need to define first an integrated of order 0 or $\mathrm{I}(0)$ process. We define a process $\left\{x_{t}, t=0, \pm 1, \ldots\right\}$ as integrated of order 0 (and denoted as $\mathrm{x}_{\mathrm{t}} \approx \mathrm{I}(0)$ ) if it is a covariance stationary process with a spectral density function that is positive and finite at the zero frequency. Alternatively, it can be defined in the time domain as a process where the infinite sum of the autocovariances is finite. Having said this, a process is integrated of order $d$, (and denoted as $\mathrm{x}_{\mathrm{t}} \approx \mathrm{I}(\mathrm{d})$ ) if it can be represented as

$$
(1-L)^{d} x_{t}=u_{t}, \quad t=0, \pm 1, \ldots
$$

with $\mathrm{x}_{\mathrm{t}}=0$ for $\mathrm{t} \leq 0$, and $\mathrm{d}>0$, where $L$ is the lag-operator $\left(L x_{t}=x_{t-1}\right)$ and $u_{t}$ is $\mathrm{I}(0)$. By allowing $d$ to be fractional, we permit a much richer degree of flexibility in the dynamic specification of the series, not achieved when using the classical approaches based on integer differentiation, i.e., $d=0$ (for stationarity) and $d=1$ (for nonstationarity). Processes with $d>0$ in (1) display the property of "long memory", characterized in this way because the spectral density function of the process is unbounded at its origin. Note that under fractional integration, if $d$ is smaller than 0.5 the process is still covariance stationary and if $d$ is smaller than 1 , it is mean reverting with shocks disappearing in the long run.

The methodology employed here to estimate the fractional differencing parameter is parametric and based on the Whittle function in the frequency domain (Dahlhaus, 1989). Other parametric and semiparametric methods based on both the time and the frequency domain produced essentially the same type of results. 


\section{Data and Empirical Results}

For each of the eight countries (Argentina (ARG), Brazil (BRA), China (CHN), Germany (GER), Japan (JPN), South Africa (ZAR), the United Kingdom (UK) and the United States of America (US)), we use three different inflation measures at monthly frequency. Year-on-year official inflation rates are calculated as the rate of change of CPI of a specific month relative to the same month in the previous year. The official CPI data for each of the countries are sourced from the International Financial Statistics of the International Monetary Fund. The year-on-year online inflation rates are available at a daily frequency (i.e., the rate of change of the online index on the same day across two consecutive years). The daily online inflation rates are converted to monthly frequency using temporal aggregation: TA (i.e., averaging the daily year-on-year inflation rates over a specific month; depicted by country name_TA), and also based on systematic sampling: SS (i.e., we use the inflation rate of the last day of the month as the inflation rate for that specific month; depicted by country name_SS). Daily online inflation rates are obtained from the website of Professor Alberto Cavallo at: http://www.mit.edu/ afc/data/datapage-bpp.html. The start and end dates for each of the country differs ${ }^{2}$ and is purely driven by data availability of online prices. The data (official inflation rate, the inflation rate based on TA, and the same based on SS) for each country have been plotted in Figure A1 in the appendix of the paper.

We display in Table 1 the estimates of $d$ along with their corresponding 95\% confidence intervals. Specifically, we present the results for the three cases: i) no regressors, ii) an intercept and iii) an intercept with a linear trend by means of the model

\footnotetext{
${ }^{2}$ While all the data ends in July, 2015, the starting dates are as follows: Argentina: November, 2008; Brazil: October, 2008; China: January 2011; Germany: March, 2010; Japan: October, 2011; South Africa: November, 2011; United Kingdom and United States of America: July, 2009.
} 
of Bloomfield (1973). ${ }^{3}$ For each of the countries, we present the estimates of $\mathrm{d}$ for the three alternative measures of monthly inflation rates. ${ }^{4}$

\section{[Insert Table 1 about here]}

As shown in Table 1, when official inflation rates are used, the null hypothesis of $d=1$ cannot be rejected for any of the countries, except for South Africa where the estimated value of $d$ is found to be smaller than 1 and thus showing mean reversion. When inflation rates are calculated based on online prices, the estimates of the degree of persistence are lower than when using official consumer price indexes, especially in the cases of Argentina, Brazil, China and the UK. The differences in the degree of persistence due to the alternative measures of inflation rates are particularly relevant in the cases of Brazil and South Africa, though in the four cases above the estimates of persistence are significantly different in the statistical sense. While in the case of Brazil, official inflation rates could be considered I(1) processes, the results suggest that $d<1$ when inflation rates are calculated based on online prices. On the contrary, in the case of South Africa, online inflation rates could be considered I(1) processes, while the results suggest that $d<1$ for official inflation rates, though in this case, the confidence intervals are so wide that we cannot infer any statistical difference in the degree of integration.

\footnotetext{
${ }^{3}$ We also estimated a model with white noise errors. However, our results were qualitatively similar. Given that the model with Bloomfield errors produced a better fit, we have presented the results from this model to save space. Complete details of the results from the model with white noise errors are available upon request from the authors. In addition, to check for robustness, we conducted estimation based on the Whittle's semiparametric approach, where no functional form is imposed on the error term. Again our results were qualitatively similar to those reported in Table 1, and also for those obtained under the (unreported) white noise error based results, for various bandwidths considered. Complete details of these results are available upon request from the authors.

${ }^{4}$ For the sake of completeness, we also estimated the long-memory parameter for the daily online inflation rates using different model specifications, error structure and estimation methodologies; the estimates were exceptionally persistent with values exceeding 1.5 . Complete details of these results are available upon request from the authors.
} 


\section{Conclusions}

This paper examines the degree of persistence of inflation rates in a sample of countries that include Argentina, Brazil, China, South Africa, Germany, Japan, the UK and the US using both official CPI and online prices to measure inflation rates. The main results suggest that the degree of persistence, estimated by the fractional integration order, is smaller when using online price indexes, mainly in the cases of Argentina, Brazil, China and the UK. Based on these results, and assuming that online prices measure consumer prices more accurately than official CPIs, we could presume that the degree of inflation persistence is lower than that obtained in the economic literature, since it has always been estimated when using official price indexes. Therefore, and based on the literature, a lower inflation persistence in these countries will imply a higher efficacy of the monetary policies directed to increase income or to control prices. The differences found in the degree of persistence using both official and online prices also suggest the need of using accurate measures of inflation rates before important policy actions are designed. 


\section{References}

Abraham, K.G. 1997. The CPI Comission: Discussion. American Economic Review 87, 94-95.

Alvarez, F., Lippi, F. and Le Bihan, H. 2016. The real effects of monetary shocks in sticky price models: a sufficient statistic approach. American Economic Review, forthcoming.

Amano, R. 2007. Inflation persistence and monetary policy: A simple result. Economics Letters 94, 26-31.

Barsky, R.B. 1987. The Fisher hypothesis and the forecastability and persistence of inflation. Journal of Monetary Economics 19, 3-24.

Bloomfield, P. 1973. An exponential model in the spectrum of a scalar time series. Biometrika 60, 27-226.

Boskin, M.J. and Jorgenson, D.W. 1997. Implications of overstating inflation for indexing government programs and understanding economic progress. American Economic Review, Papers and Proceedings 87, 89-93.

Cavallo, A. 2013. Online vs official price indexes: Measuring Argentina's inflation. Journal of Monetary Economics 60, 152-165.

Cavallo, A., Cruces, G. and Perez-Truglia, R. 2014. Inflation expectations, learning and supermarket prices: evidence from field experiments. NBER Working Paper 20576.

Cavallo, A. and Rigobon, R. 2016. The Billion Prices Project: Using online prices for measurement and research. Journal of Economic Perspectives, forthcoming.

Christiano, L., Einchenbaum, M. and Evans, C. 2005. Nominal rigidities and the dynamics effects of shocks to monetary policy. Journal of Political Economy 113, 1-45.

Cuestas, J.C. and Harrison, B. 2010. Inflation persistence and nonlinearities in Central and Eastern European countries. Economics Letters 106, 81-83.

Dahlhaus, R. 1989. Efficient parameter estimation for self-similar process. Annals of Statistics 17, 1749-1766.

Diewert, W.E. 1976. Exact and superlative index numbers. Journal of Econometrics 4, $115-145$

Diewert, W.E. 1995. Axiomatic and Economic approaches to elementary price indexes. NBER working paper 5104.

Dornbusch, R. 1976. Expectations and exchange rate dynamics. Journal of Political Economy 84, 1161-1176.

Galí, J. and Gertler, M. 1999. Inflation dynamics: A structural econometric analysis. Journal of Monetary Economics 44, 195-222. 
Gordon, R. and Griliches, Z. 1997. Quality change and new products. American Economic Review, Papers and Proceedings 87, 84-88.

Gorodnichenko, Y., Sheremirov, V. and Talavera, O. 2014. Price setting in online markets: Does IT click? NBER Working Paper Series 20819.

Gorodnichenko, Y. and Talavera, O. 2014. Price setting in online markets: Basic facts, international comparisons and cross-border integration. NBER Working Paper 20406.

Griliches, Z. 1961. Hedonic price indexes and quality change, in G. Stigler, Ed. The Price Statistics of the Federal Government. New York, National Bureau of Economic Research.

Hassler, U. and Wolters, J. 1995. Long memory in inflation rates: International evidence. Journal of Business and Economic Statistics 13, 37-45.

Hassler, U. and Meller, B. 2014. Detecting multiple breaks in long memory: the case of US inflation. Empirical Economics 46, 653-680.

Hausman, J., 1997. Cellular telephones, new products and the CPI. NBER Working Paper 5982.

Hsu, C.C. 2005. Long memory or structural changes: An empirical examination on inflation rates. Economics Letters 88, 289-294.

Lee, J. 2005. Estimating memory parameter in the US inflation rate. Economics Letters 87, 207-210.

Levin, A.T. and Williams, J.C. 2003. Robust monetary policy with competing reference models. Journal of Monetary Economics 50, 945-975.

Martins, L.F. and Rodrigues, P.M.M. 2014. Testing for persistence change in fractionally integrated models: An application to world inflation rates. Computational Statistics and Data Analysis 76, 502-522.

Nelson, C.R. and Schwert, G.W. 1977. Short-term interest rates as predictors of inflation: On testing the hypothesis that the real rate of interest is constant. American Economic Review 67, 478-486.

Noriega, A.E. and Ramos-Francia, M. 2009. The dynamics of persistence in US inflation. Economics Letters 105, 168-172.

Rudebusch, G.D. 2002. Assessing nominal income rules for monetary policy with model and data uncertainty. Economic Journal 112, 402-432. 
Table 1. Persistence of monthly official and online inflation rates

\begin{tabular}{|c|c|c|c|}
\hline ARGENTINA & No regressors & An intercept & A linear time trend \\
\hline ARG & $0.84(0.56,1.40)$ & $1.11(0.80,1.53)$ & $1.12(0.80,1.53)$ \\
\hline ARG_TA & $0.57(0.26,1.14)$ & $0.97(0.54,1.42)$ & $0.96(0.41,1.40)$ \\
\hline ARG_SS & $0.61(0.27,1.21)$ & $1.06(0.68,1.49)$ & $1.06(0.68,1.49)$ \\
\hline BRAZIL & No regressors & An intercept & A linear time trend \\
\hline BRA & $0.92(0.66,1.30)$ & $1.09(0.72,1.53)$ & $1.09(0.72,1.56)$ \\
\hline BRA_TA & $0.67(0.41,1.05)$ & $0.58(0.40,0.84)$ & $0.44(0.18,0.84)$ \\
\hline BRA_SS & $0.50(0.24,0.89)$ & $0.58(0.43,0.81)$ & $0.35(0.03,0.77)$ \\
\hline CHINA & No regressors & An intercept & A linear time trend \\
\hline $\mathrm{CHN}$ & $1.02(0.69,1.47)$ & $1.23(0.78,1.81)$ & $1.24(0.77,1.81)$ \\
\hline CHN_TA & $0.88(0.53,1.54)$ & $0.63(0.47,1.04)$ & $0.37(-0.07,1.04)$ \\
\hline CHN_SS & $0.79(0.47,1.37)$ & $0.60(0.42,1.06)$ & $0.37(0.02,1.07)$ \\
\hline GERMANY & No regressors & An intercept & A linear time trend \\
\hline GER & $1.07(0.90,1.32)$ & $1.04(0.87,1.26)$ & $1.04(0.86,1.24)$ \\
\hline GER_TA & $1.07(0.85,1.39)$ & $1.07(0.87,1.36)$ & $1.07(0.87,1.36)$ \\
\hline GER_SS & $1.03(0.82,1.33)$ & $1.00(0.81,1.26)$ & $1.00(0.81,1.26)$ \\
\hline JAPAN & No regressors & An intercept & A linear time trend \\
\hline JPN & $0.96(0.61,1.38)$ & $0.97(0.62,1.39)$ & $0.96(0.47,1.39)$ \\
\hline JPN_TA & $0.97(0.20,1.89)$ & $1.00(0.26,1.92)$ & $1.03(0.35,1.94)$ \\
\hline JPN_SS & $0.98(0.07,2.07)$ & $1.33(0.13,2.12)$ & $1.33(0.71,2.14)$ \\
\hline SOUTH AFRICA & No regressors & An intercept & A linear time trend \\
\hline ZAR & $0.53(0.07,1.31)$ & $0.23(-0.41,0.96)$ & $0.44(-0.62,0.99)$ \\
\hline ZAR_TA & $0.61(0.07,1.40)$ & $0.58(0.11,1.05)$ & $0.62(0.07,1.07)$ \\
\hline ZAR_SS & $0.60(0.09,1.38)$ & $0.64(0.32,1.05)$ & $0.64(0.32,1.05)$ \\
\hline United Kingdom & No regressors & An intercept & A linear time trend \\
\hline UK & $1.07(0.88,1.38)$ & $1.08(0.86,1.46)$ & $1.08(0.85,1.46)$ \\
\hline UK_TA & $0.89(0.70,1.15)$ & $0.78(0.58,1.06)$ & $0.78(0.55,1.06)$ \\
\hline UK_SS & $0.94(0.73,1.22)$ & $0.93(0.73,1.22)$ & $0.94(0.72,1.22)$ \\
\hline $\begin{array}{c}\text { United States of } \\
\text { America }\end{array}$ & No regressors & An intercept & A linear time trend \\
\hline US & $0.70(0.42,1.08)$ & $0.85(0.36,1.30)$ & $0.88(0.44,1.28)$ \\
\hline US_TA & $0.95(0.68,1.38)$ & $1.07(0.76,1.56)$ & $1.08(0.78,1.47)$ \\
\hline US_SS & $0.89(0.67,1.29)$ & $1.09(0.75,1.53)$ & $1.08(0.79,1.47)$ \\
\hline
\end{tabular}

Note: The values in parenthesis refer to the 95\% confidence bands for the values of $d$. We report in bold the significance cases, according to the deterministic terms; TA (SS): monthly version of daily inflation rates based on Temporal Aggregation (Systematic Sampling). 


\section{APPENDIX}

Figure A1. Alternative inflation measures: Official inflation rates, monthly version of daily inflation rates based on Temporal Aggregation and Systematic Sampling

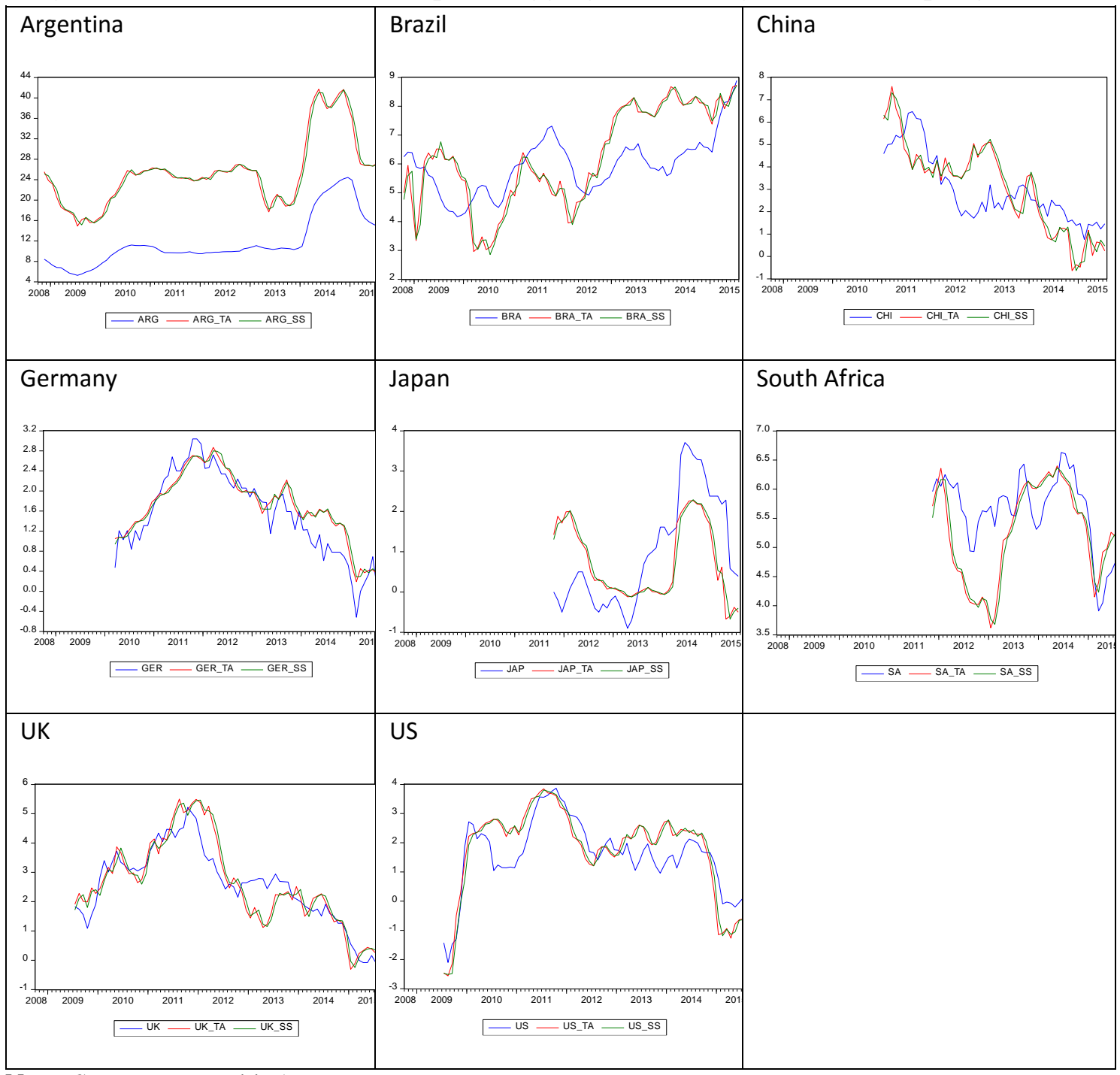

Note: See Notes to Table 1. 